\title{
Eventos de incidencia en políticas públicas
}

\author{
Catalina Arboleda Ramírez \\ Gloria Isabel Puerta Escobar \\ Ana María Mejía Zuluaga \\ Laura Cristina Jaramillo Jaramillo \\ Santiago Isaza Arango \\ FUNDACIÓN LUKER
}

Dentro de la alianza que se ha establecido en el proyecto Escuela Activa Urbana, hay actores como la Fundación Ford y la Fundación Empresarios por la Educación que permanentemente impulsan iniciativas para que el proyecto trascienda el papel que ejerce al interior de las instituciones educativas en cuanto al mejoramiento de la calidad de la educación y llegue a escenarios más amplios a través del impacto en políticas públicas. Para este efecto se han diseñado tres eventos durante el 2007 que buscan sensibilizar a autoridades educativas del municipio y a actores de la comunidad educativa en general sobre la importancia de incidir en políticas públicas con proyectos de abatimiento de la inequidad educativa; adicionalmente se busca presentar este tema frente a la opinión pública para buscar el apoyo de la misma respecto al proyecto. Los eventos son:

- $\quad$ Diálogo público No. 1, mayo de 2007

- Diálogo público No. 2, agosto de 2007

- $\quad$ Seminario internacional, agosto de 2007

A continuación se presenta una reseña ejecutiva de los tres eventos con sus temáticas y objetivos: 


\begin{tabular}{|c|c|c|}
\hline & Primer Diálogo Público & Segundo Diálogo Público \\
\hline Tema & $\begin{array}{l}\text { Fortalecimiento profesional y personal } \\
\text { de maestros y maestras encaminados } \\
\text { al abatimiento de la inequidad. Es- } \\
\text { cuela Activa Urbana, un modelo esco- } \\
\text { lar para la equidad. }\end{array}$ & $\begin{array}{l}\text { Incidencia en el desarrollo y dignidad humana en estu- } \\
\text { diantes involucrados en proyectos encaminados a dismi- } \\
\text { nuir la inequidad. }\end{array}$ \\
\hline Fecha & Mayo 25 de 2007 & Agosto 30 de 2007 \\
\hline Lugar & $\begin{array}{l}\text { Manizales, Caldas. Escuela Nacional } \\
\text { de Enfermería }\end{array}$ & Manizales, Caldas. Escuela Nacional de Enfermería \\
\hline $\begin{array}{l}\text { Número de } \\
\text { Asistentes }\end{array}$ & 43 personas & 100 personas \\
\hline $\begin{array}{l}\text { Tipo de } \\
\text { evento }\end{array}$ & Conversatorio & Conversatorio \\
\hline $\begin{array}{l}\text { Institución } \\
\text { Ejecutora }\end{array}$ & $\begin{array}{l}\text { Fundación Luker, Fundación Empre- } \\
\text { sa-rios por la Educación y Red PRO- } \\
\text { PONE. Apoyado por la Secretaría de } \\
\text { Educación Municipal, Fundación Gé- } \\
\text { nesis y Funda-ción Metrópoli }\end{array}$ & $\begin{array}{l}\text { Fundación Luker, Fundación Empresarios por la Educa- } \\
\text { ción y Red PROPONE. Apoyado por la Secretaría de } \\
\text { Educación Municipal, Fundación Génesis y Fundación } \\
\text { Metrópoli }\end{array}$ \\
\hline Expositores & $\begin{array}{l}\text { JORGE MORALES PARRA Rector } \\
\text { de la Escuela Normal Superior de Ma- } \\
\text { nizales. } \\
\text { ALVARO MAYA RESTREPO Director } \\
\text { de Núcleo adscrito a la Secretaría de } \\
\text { Educación Municipal. } \\
\text { CRISTOBAL TRUJILLO RAMíREZ } \\
\text { Coordinador Instituto Universitario, } \\
\text { Administrador de Empresas. } \\
\text { OSCAR CORREA MARIN } \\
\text { Ingeniero Industrial, Universidad Na- } \\
\text { cional de Colombia. } \\
\text { Especialista en Economía, Universi- } \\
\text { dad Nacional de Colombia } \\
\text { Especialista en Finanzas, Universidad } \\
\text { EAFIT. }\end{array}$ & $\begin{array}{l}\text { Dr. HUGO ZEMELMAN: } \\
\text { Ponente principal del dialogo, de nacionalidad chilena, } \\
\text { actualmente profesor - investigador en el Colegio de } \\
\text { México. } \\
\text { Dra. ESTELA BEATRIZ QUINTAR } \\
\text { Segunda ponente principal, de nacionalidad argentina, } \\
\text { actualmente asesora en el diseño de la Maestría en Di- } \\
\text { dáctica y Conciencia Histórica, Coordinadora del Diplo- } \\
\text { mado "Didáctica y Conciencia Histórica", Asesora del } \\
\text { equipo de investigación del UPN Pachuca. - del Colegio } \\
\text { de México } \\
\text { Dra. LATIFE ABDALA DE PAZ: } \\
\text { Rectora del Colegio Integrado Villa Pilar - Modelo Escola } \\
\text { Escuela Activa Urbana }\end{array}$ \\
\hline $\begin{array}{l}\text { Objetivo del } \\
\text { evento }\end{array}$ & $\begin{array}{l}\text { Reflexionar sobre la importancia de la } \\
\text { formación de docentes y su inciden- } \\
\text { cia en la calidad de la educación en el } \\
\text { municipio de Manizales. }\end{array}$ & $\begin{array}{l}\text { Reflexionar sobre la incidencia en el desarrollo y dignidad } \\
\text { humana en estudiantes involucrados en proyectos enca- } \\
\text { minados a disminuir la inequidad. }\end{array}$ \\
\hline
\end{tabular}


Teniendo como principales ejes los siguientes interrogantes:

¿Cuál es su percepción frente a las condiciones de cualificación profesional que presenta el profesorado en el país y en Manizales?

¿Qué relación guardan estas condiciones con la calidad educativa?

¿Cuál es el rol que deben cumplir los docentes en procura de mejorar la calidad de educación? Y frente a dicho rol.

¿Qué condiciones se requieren para el respecto?

A partir de los problemas identificados dentro del ejercicio profesional docente ¿qué alternativas identifica para su superación?

¿Cómo pueden ser llevadas al escenario de las políticas públicas estas alternativas?
¿Cómo podemos entender el tema "subjetividad" en el ámbito educativo? y ¿qué reflexión le merece la relación entre los logros de aprendizaje y la mejora del desarrollo personal y social? (autoestima, las habilidades sociales de los niños, como la participación, y la convivencia).

El proyecto Modelos Escolares para la Equidad - MEPE busca atacar las condiciones que impiden la permanencia de los estudiantes en el sistema educativo; así como el mejoramiento de la calidad educativa, haciendo las prácticas de enseñanza - aprendizaje, pertinentes a los contextos de las instituciones educativas y sus comunidades. De esta manera se busca que el sistema retenga a los estudiantes, garantizando la permanencia y que lo que se estudia sea útil para la vida de los mismos. En este orden de ideas, ¿Qué elementos destacaría usted como de gran importancia para los estudiantes, los maestros, los miembros de la comunidad educativa en referencia al desarrollo y afianzamiento del crecimiento personal de dichos actores escolares?

Si se trata de promover cambios en los aspectos propios de la subjetividad de los actores escolares (cambios que contribuyan a la equidad y mejoramiento escolar) ¿cómo sería posible llevar estas intenciones al terreno de las políticas públicas educativas?

PARA ESTUDIANTES Y/O PROFESORES-AS:

Su participación en el Proyecto EAU-MEPE ¿qué cambios significó en el ámbito personal y de relación con las demás personas? Relato de su experiencia En su concepto, ¿cuáles son las condiciones que presentan los actores sociales (estudiantes-profesorado) en el país y en la región que determinan la necesidad de mejorar sus condiciones de desarrollo personal y social? ¿Qué otros elementos o temas, que escapan a las anteriores preguntas considera importante poner de manifiesto durante su exposición? 


\begin{tabular}{|c|c|c|}
\hline $\begin{array}{l}\text { Resultados } \\
\text { esperados }\end{array}$ & $\begin{array}{l}\text { Motivar la discusión tanto en la comu- } \\
\text { nidad educativa como en otras entida- } \\
\text { des interesadas en la educación, so- } \\
\text { bre la importancia de la cualificación } \\
\text { docente, su fortalecimiento profesio- } \\
\text { nal y personal, y su incidencia en la } \\
\text { calidad educativa. } \\
\text { Promover la participación ciudadana } \\
\text { en diálogos y eventos relacionados } \\
\text { con la educación. } \\
\text { Posicionar el tema educativo en la } \\
\text { agenda pública local } \\
\text { Impulsar a la Secretaría de Educación } \\
\text { de Manizales a participar en eventos } \\
\text { de rendición de cuentas. }\end{array}$ & $\begin{array}{l}\text { Socializar y reflexionar frente a las críticas constructivas } \\
\text { de las miradas internacionales con respecto a los proyec- } \\
\text { tos de calidad de la educación que se ejecutan en los di- } \\
\text { ferentes países, buscando desarrollar soluciones que nos } \\
\text { permitan mejorar los errores del modelo escolar escuela } \\
\text { activa urbana que se desarrolla en Caldas. } \\
\text { Evidenciar experiencias significativas de los colegios que } \\
\text { desarrollan el modelo escolar de Escuela Activa Urbana } \\
\text { y concientizar al público acerca de los posibles riesgos } \\
\text { en los que se podría caer sino se pensara en aspectos } \\
\text { importantes como el currículo y la formación integral de } \\
\text { los estudiantes, el papel del docente en el aula de clase } \\
\text { etc... } \\
\text { Promover un espacio de participación entre docentes, } \\
\text { rectores y actores claves del sistema educativo que les } \\
\text { permita exponer sus diferentes puntos de vista frente la } \\
\text { subjetividad del ser. }\end{array}$ \\
\hline
\end{tabular}

\begin{tabular}{|c|c|}
\hline & Seminario Nacional sobre Calidad y Equidad Educativa \\
\hline Tema & Seminario Nacional de Escuela Activa Urbana \\
\hline Fecha & Agosto 8 de 2007 \\
\hline Lugar & Manizales, Caldas. Termales del Otoño \\
\hline $\begin{array}{l}\text { Número de } \\
\text { asistentes }\end{array}$ & 690 personas \\
\hline $\begin{array}{l}\text { Institución } \\
\text { ejecutora }\end{array}$ & $\begin{array}{l}\text { Fundación Luker, Empresarios por la Educación, Alcaldía de Manizales, Fundación Génesis, Ford } \\
\text { Foundation, Metrópoli, IBM }\end{array}$ \\
\hline Expositores & $\begin{array}{l}\text { MARIA CONSTANZA MONTOYA NARANJO } \\
\text { Secretaria de Educación Municipal } \\
\text { ANA MARIA GONZALEZ DE LONDOÑO } \\
\text { Abogada, Bilingüe, especialista en derecho comercial y planeación estratégica, con especialización } \\
\text { en alta gerencia y en gestión para la cooperación internacional. Gerente de la Fundación Luker. } \\
\text { ALEJANDRO SANZ SANTAMARIA } \\
\text { Autor del artículo: Dimensión formativa de la educación. Ingeniero Industrial con Ph. D en econo- } \\
\text { mía y M.S en investigación de operaciones. } \\
\text { JOSE LUIS VILLAVECES CARDOSO } \\
\text { Exsecretario de educación de Bogotá } \\
\text { Químico de la Universidad Nacional de Colombia y Magíster y phD de la Universidad de Lovaina, } \\
\text { de Bélgica } \\
\text { MARIA AMELIA PALACIOS VALLEJO } \\
\text { Oficial del programa reforma educacional Fundación Ford para el área andina y el cono sur. }\end{array}$ \\
\hline $\begin{array}{l}\text { Objetivo del } \\
\text { evento }\end{array}$ & $\begin{array}{l}\text { Generar un espacio de reflexión alrededor de la equidad y calidad de la educación pública y la } \\
\text { incidencia a través de modelos pedagógicos activos en estas. }\end{array}$ \\
\hline
\end{tabular}




\begin{tabular}{|c|c|}
\hline Temática & 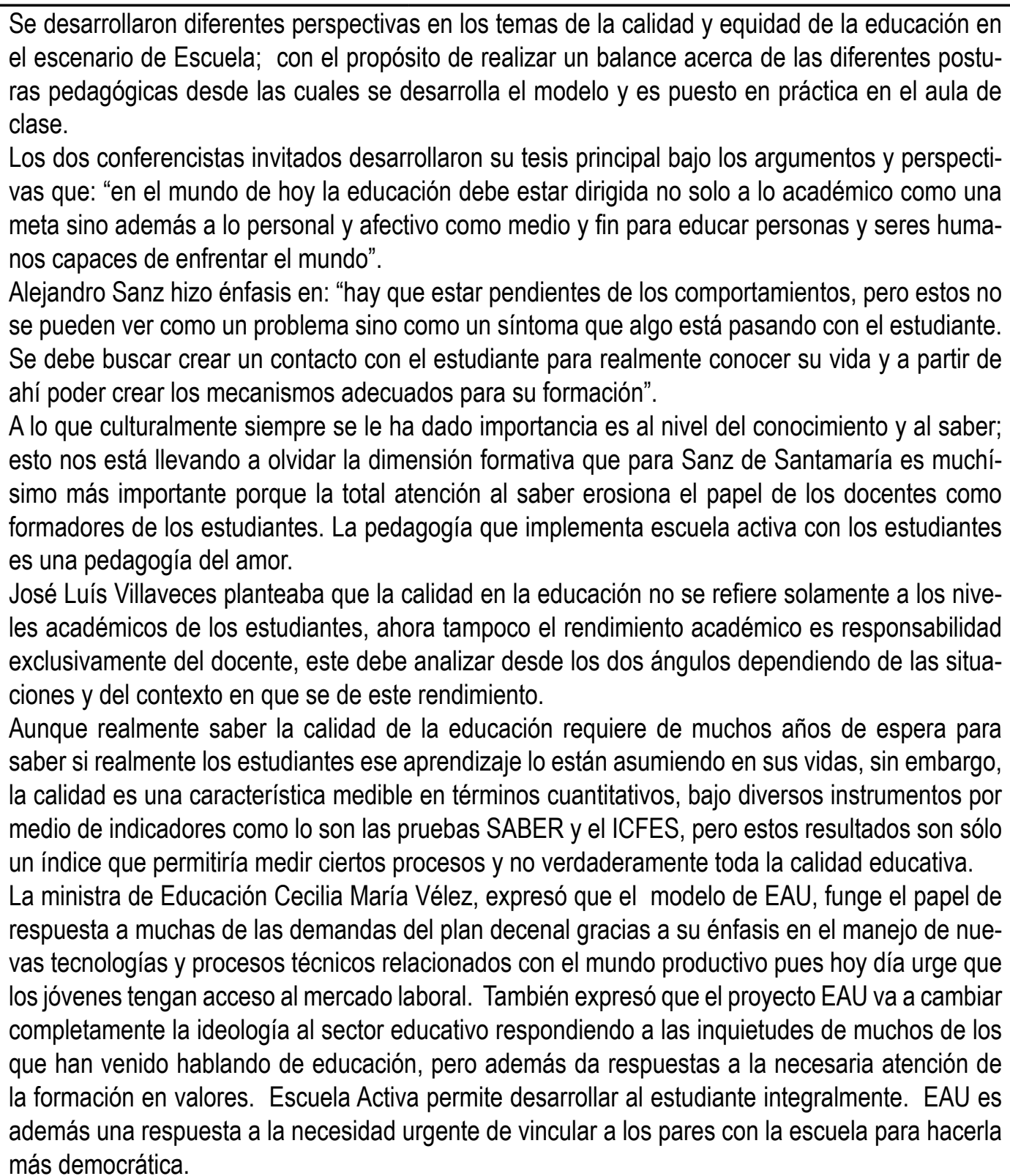 \\
\hline
\end{tabular}

Adicional a los eventos planteados anteriormente sobre incidencia en políticas públicas, el proyecto Escuela Activa Urbana también ha estado presente en los siguientes escenarios políticos, donde se puede evidenciar la incidencia del mismo:

- Visión Manizales 2019

- Plan de desarrollo de la actual Alcaldía

- Se ha presentado al $100 \%$ de los candidatos actuales para la Alcaldía de Manizales.

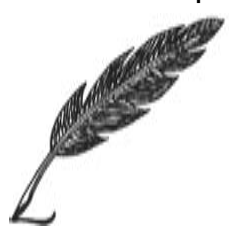

